\title{
Soil-geosynthetic inclined plane shear behavior: influence of soil moisture content and geosynthetic type
}

\section{Maria-Lurdes Lopes*, Fernanda Ferreira, José Ricardo Carneiro and Castorina Silva Vieira}

This paper deals with the inclined plane shear on three different geosynthetics (a geocomposite (GC), a non-woven geotextile (GTX), and an extruded geogrid (GGR)) with a residual soil from granite. Soil and geosynthetic properties, test equipment, and procedures are described. The influence of soil moisture content and geosynthetic type on soil-geosynthetic interaction behavior is discussed by analyzing the results of the inclined plane shear tests. The main conclusions that can be outlined from the present study are the following: (1) the influence of soil moisture content was relevant for the soil-GTX and soil-GC interfaces. Indeed, the resistance of those interfaces decreased with the increase of soil moisture content. No significant differences were observed between the behavior of those geosynthetics; (2) the influence of soil moisture content on the behavior of the soil-GGR interface was less evident. A slight decrease on the interface friction angle was only observed for the highest soil moisture content; (3) the dry soil-GGR interface resistance was lower than that observed for the other two geosynthetics due to the relevance of soil-soil friction at the GGR apertures, to the high percentage of fines of the soil used in the research $\left(D_{50}=1.00 \mathrm{~mm}\right)$, and to the smoother solid lateral surface of the extruded GGR when compared with the surface of the GTX or GC.

Keywords: Geosynthetics, Soil-geosynthetic interaction, Inclined plane shear behavior, Soil moisture content

\section{Notation}

Basic SI units are given in parentheses.

$\beta=$ slipping angle of upper box $\left({ }^{\circ}\right)$

$\tau=$ shear stress $\left(\mathrm{N} \mathrm{m}^{-2}\right)$

$\gamma_{\mathrm{d}}^{\max }=$ maximum dry unit weight of soil $\left(\mathrm{N} \mathrm{m}^{-3}\right)$

$\gamma_{\mathrm{d}}^{\min }=$ minimum dry unit weight of soil $\left(\mathrm{N} \mathrm{m}^{-3}\right)$

$\sigma_{\mathrm{n}}=$ normal stress $\left(\mathrm{N} \mathrm{m}^{-2}\right)$

$\phi_{\mathrm{sg}}=$ friction angle of soil-geosynthetic interface $\left.{ }^{\circ}\right)$

$A=$ soil-geosynthetic contact area $\left(\mathrm{m}^{2}\right)$

$C_{\mathrm{u}}=$ uniformity coefficient of soil (dimensionless)

$C_{\mathrm{c}}=$ curvature coefficient of soil (dimensionless)

$D_{10}=$ diameter corresponding to $10 \%$ passing of soil $(\mathrm{m})$

$D_{30}=$ diameter corresponding to $30 \%$ passing of soil (m)

Faculty of Engineering, University of Porto, Porto, Portugal

*Corresponding author, email Icosta@fe.up.pt
$D_{50}=$ diameter corresponding to $50 \%$ passing of soil (m)

$D_{\text {máx }}=$ maximum diameter of soil (m)

$D_{\text {min }}=$ minimum diameter of soil $(\mathrm{m})$

$f_{(\beta)}=$ force required to restrain the empty upper box at inclination of $\beta(\mathrm{N})$

$F_{\mathrm{v}}=$ vertical force acting on soil-geosynthetic interface $(\mathrm{N})$

$I_{\mathrm{D}} \quad=$ relative density of soil $(\%)$

$w_{\text {opt }}=$ Optimum soil moisture content $(\%)$

\section{Introduction}

Inclined plane shear tests are used to characterize the interaction mechanism at soil-geosynthetic or geosynthetic-geosynthetic interfaces when the relative movement that occurs is of shearing and the geosynthetics are placed over an inclined surface.

Inclined plane shear behavior at soil-geosynthetic and geosynthetic-geosynthetic interfaces have been studied by several authors (among others: Izgin and Wasti, 1998; 


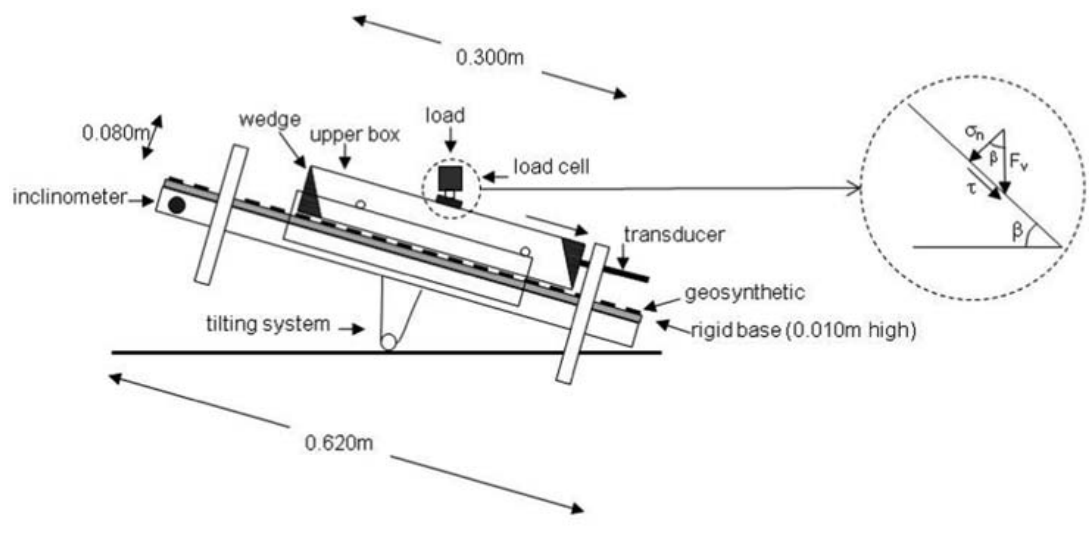

a)

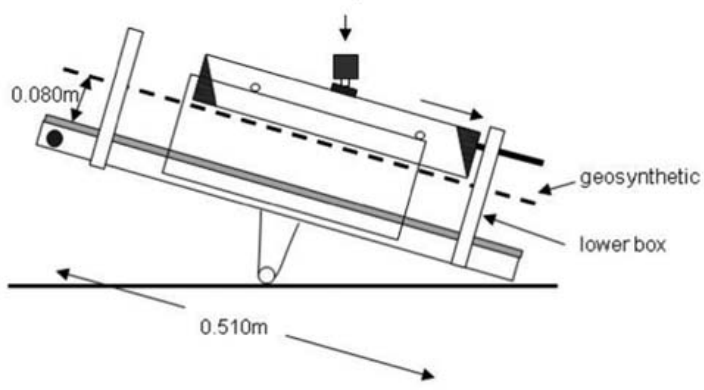

b)

1 Schematic representation of the inclined plane shear test apparatus: $a$ for test method 1 and $b$ for test method 2

Wasti and Özdüzgün, 2001; Costa-Lopes et al., 2001; Briançon et al., 2002; Palmeira et al., 2002; Reyes Ramirez and Gourc, 2003; Narejo, 2003; Pitanga et al., 2009; Eid, 2011; Briançon et al., 2011, Lopes, 2013).

With the aim of obtaining additional data on soilgeosynthetic interface behavior on inclined plane shear and on the influence on it of the soil moisture content and the geosynthetic type, this paper studies the interaction between different types of geosynthetics (a geocomposite (GC), a geotextile (GTX), and a geogrid (GGR)) and a residual soil from granite (with different moisture contents), by performing inclined plane shear tests according to EN ISO 12957-2 (Determination of friction characteristics. Part 2: inclined plane test).

\section{Equipment and test procedures}

The inclined plane shear test allows characterizing the resistance of soil-geosynthetic interfaces, by determining the minimum angle to the horizontal to which the sliding takes place between the soil and the geosynthetic.

The inclined plane shear test apparatus and test procedures used in the present research are exhaustively described in Costa-Lopes et al. (2001) and Lopes (2013).

The test can be carried out using two different methods: 1. with a rigid support for the geosynthetic (Fig. 1a);

2. with the geosynthetic supported on a lower box, which is filled with soil (Fig. 1b).

The inclined plane shear test apparatus (Fig. 1) is a dismountable structure that includes:
- a rigid and smooth base, 0.620 m long, 0.430 m wide, and $0 \cdot 010 \mathrm{~m}$ high; the geosynthetic is placed on this base to carry out test method 1 ;

- a rigid lower box, with internal dimensions of $0.510 \mathrm{~m}$ long, $0.350 \mathrm{~m}$ wide, and $0.080 \mathrm{~m}$ high, that is filled with soil over which the geosynthetic is placed on test method 2; - a rigid upper box, with internal dimensions of $0 \cdot 300 \mathrm{~m}$ long, $0 \cdot 300 \mathrm{~m}$ wide, and $0 \cdot 080 \mathrm{~m}$ high, filled with soil that slides over the geosynthetic.

The rigid base can be raised at the rate of $0.5^{\circ} \mathrm{min}^{-1}$ (test speed) and lowered, at the end of the test, at the rate of $2^{\circ} \min ^{-1}$.

The normal force is applied by weights transmitted to a rigid steel plate that covers the whole interior area of the upper box. The assurance that the normal force passes through the center of gravity of the upper box is guaranteed by two wedges inclined one vertical to two horizontal and placed on the frontal and back walls of this box. A load cell, located between the load beam and the rigid plate, is used to measure the normal force applied.

The equipment includes three safety devices:

- one to stop the test when the movement of the upper box exceeds $0.050 \mathrm{~m}$;

- the other two to stop the base when the maximum inclination of the equipment is reached and to stop the base at the horizontal position at the end of the test.

Costa-Lopes et al. (2001) concluded that soil-geosynthetic inclined plane shear behavior can be assessed by using test method 1 (with a rigid support for the geosynthetic) for geosynthetics with continuous lateral surfaces (e.g.: GTXs 


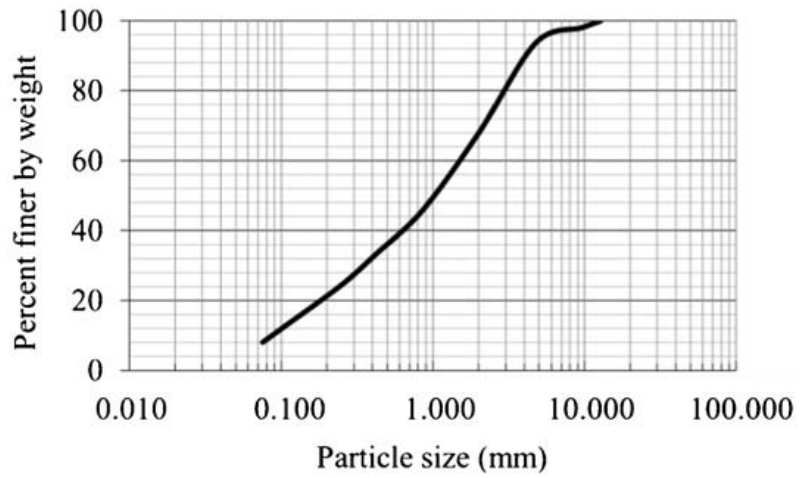

2 Soil particle size distribution

or geomembranes). The authors suggested to use test method 2 (with the geosynthetic supported on a lower box which is filled with soil) for GGRs.

This way, in the present research, the inclined plane shear tests with the GC and GTX were performed according to test method 1 and the tests with the GGR were carried out according to test method 2 .

The dimensions of the geosynthetic specimens were $0.70 \mathrm{~m}$ long and $0.43 \mathrm{~m}$ wide for test method 1 and $0.60 \mathrm{~m}$ long and $0.36 \mathrm{~m}$ wide for test method 2 .

On test method 2, the soil was poured into the box from a constant height of $0.20 \mathrm{~m}$ and placed in $0.020 \mathrm{~m}$ thick layers. Each layer was leveled and compacted to the required density using a light compacting hammer.

After fixing the geosynthetic, the upper box was assembled and aligned in the starting position. The upper

Table 1 Physical properties of the soil

\begin{tabular}{llc}
\hline Property & Unit & Value \\
\hline$D_{10}$ & $\mathrm{~mm}$ & 0.09 \\
$D_{30}$ & $\mathrm{~mm}$ & 0.35 \\
$D_{50}$ & $\mathrm{~mm}$ & $1 \cdot 0$ \\
$C_{\mathrm{u}}$ & - & $16 \cdot 9$ \\
$C_{\mathrm{c}}$ & - & $1 \cdot 0$ \\
$\gamma_{\mathrm{d}}{ }_{\text {max }}$ & $\mathrm{kN} \mathrm{m}^{-3}$ & 18.93 \\
$\gamma_{\mathrm{d}}{ }^{\mathrm{in}}$ & $\mathrm{kN} \mathrm{m}$ & $12 \cdot 85$ \\
$W_{\text {opt }}$ & $\%$ & $11 \cdot 45$ \\
\hline
\end{tabular}
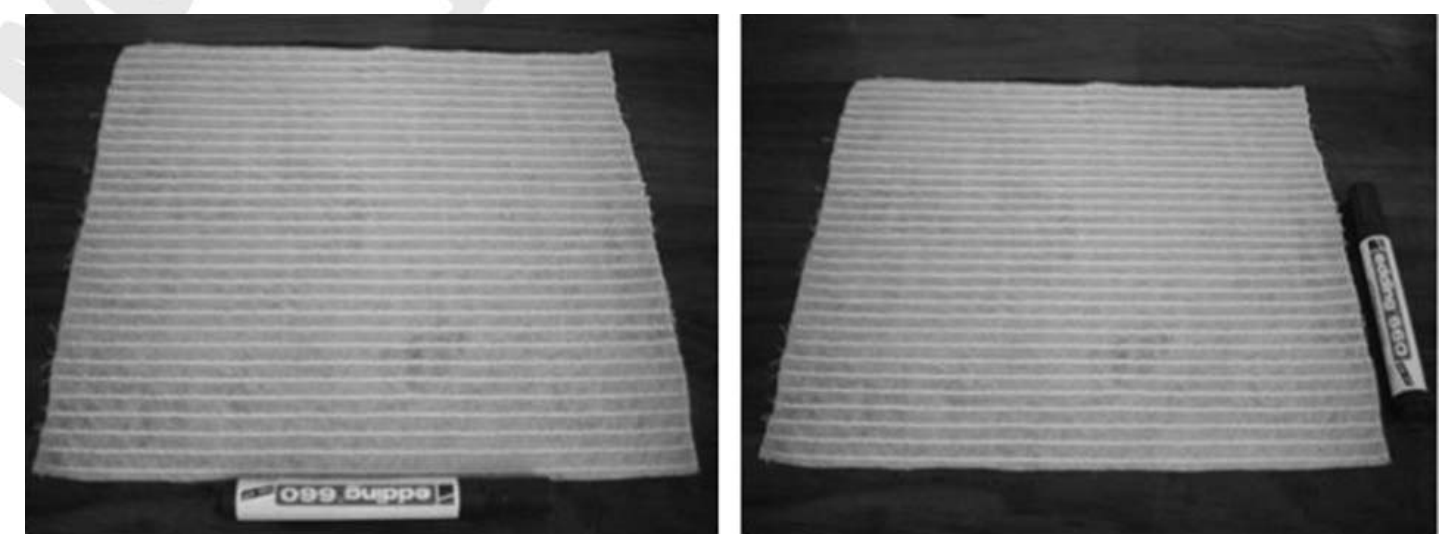

box was then filled with soil using procedures similar to the ones used in the lower box.

The rigid plate was placed and the load applied.

Finally, the test speed was chosen, the horizontality of the base was verified and the transducer and the inclinometer were set to zero.

\section{Materials \\ Soil}

The soil used in this study was a well-graded residual soil from granite. According to the Unified Soil Classification System, this soil can be classified as SW-SM (well-graded sand with silt and gravel). Figure 2 shows the particle size distribution curve of the soil and its main physical properties are provided in Table 1 . In order to take into account the difficulties in compacting soils in slopes, a conservative soil relative density $\left(I_{\mathrm{D}}\right)$ of $50 \%$ was considered. Different soil moisture contents were tested: dry, half of the optimum moisture content ( $\left.1 / 2 w_{\text {opt }}\right)$, and optimum moisture content $\left(w_{\text {opt }}\right)$.

\section{Geosynthetics}

Three different geosynthetics were selected for this research: a GC, a non-woven spunbonded GTX, and a uniaxial extruded GGR.

The GC (Fig. 3) was composed of high modulus polyester (PET) fibers, attached to a continuous filament non-woven GTX backing; the GGR (Fig. 4) was manufactured from high-density polyethylene (HDPE); the GTX (Fig. 5) was made from mechanically bonded continuous filaments of polypropylene (PP). The main properties of the geosynthetics are summarized in Table 2.

\section{Test program}

The program carried out in this study is shown in Table 3.

Each geosynthetic was tested under three vertical stresses $(5,10$, and $25 \mathrm{kPa})$ and three soil moisture contents (dry, 1/2 $w_{\text {opt }}$, and $w_{\text {opt }}$ ). The GC was tested with the PET fibers along the shear direction. Although 27 tests are reported in Table 3, each one was repeated three times and, thus, a total of 81 tests were carried out. 


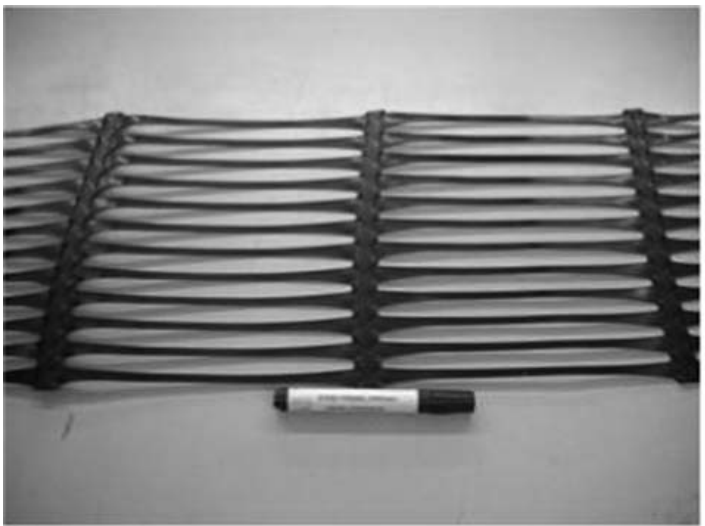

4 Extruded uniaxial geogrid

\section{Results and discussion}

Table 4 resumes the results of test T1 and Fig. 6 shows the variation of the upper box displacement with the inclination of the rigid base for the three specimens tested under the same conditions (GC, vertical stress of $5 \mathrm{kPa}$, dry soil).

The inclination for the maximum upper box displacement $(50 \mathrm{~mm})$ provides information about the slipping angle of the upper box, $\beta$, that allows deriving the friction angle of the interface, $\phi_{\mathrm{sg}}$.

The normal stress, $\sigma_{\mathrm{n}}$, applied when the slipping angle of the upper box is equal to $\beta$ can be obtained as follows:

$$
\sigma_{\mathrm{n}}=\frac{F_{\mathrm{v}} \cos \beta}{A}
$$

where $F_{\mathrm{v}}$ is the vertical force acting on the interface and $A$ is the contact area.

The shear stress $(\tau)$ at the sliding surface is defined as:

$$
\tau=\frac{F_{\mathrm{v}} \sin \beta+f_{(\beta)}}{A}
$$

where $f_{(\beta)}$ is the force required to restrain the empty upper box when the tilt table is inclined at the angle $\beta$.

It is possible to calculate the angle of friction of soilgeosynthetic interfaces, $\phi_{\mathrm{sg}}$, as follows:

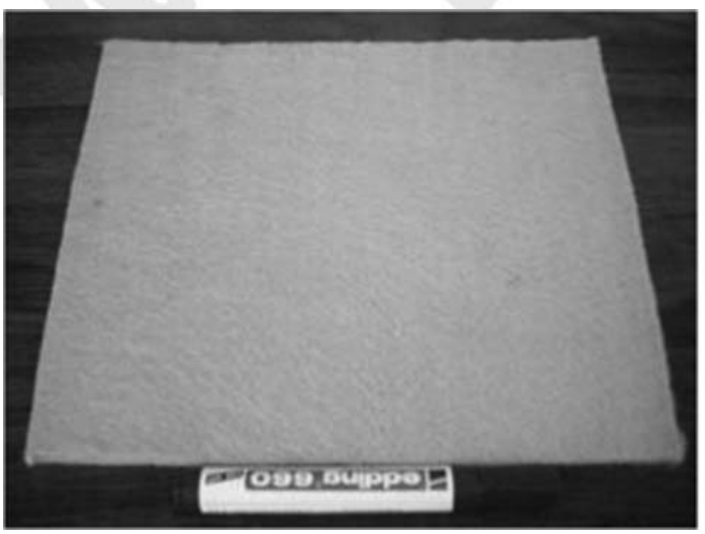

5 Non-woven geotextile

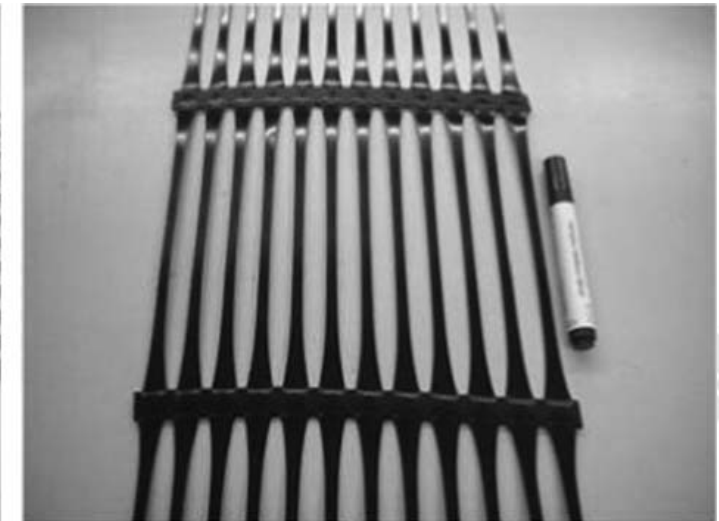

$$
\tan \phi_{\text {sg }}=\frac{\tau}{\sigma_{\mathrm{n}}} \Rightarrow \phi_{\mathrm{sg}}=\tan ^{-1} \frac{\tau}{\sigma_{\mathrm{n}}}
$$

The mean friction angle on the interface between dry

\begin{tabular}{|c|c|c|c|c|}
\hline \multirow[b]{2}{*}{ Property } & \multirow[b]{2}{*}{ Unit } & \multicolumn{3}{|c|}{ Geosynthetics } \\
\hline & & GC & GGR & GTX \\
\hline Raw material & - & PET/PP & HDPE & PP \\
\hline Mass per unit area & $\mathrm{g} \mathrm{m}^{-2}$ & 310 & 450 & 1000 \\
\hline Mean aperture size & $\mathrm{mm}$ & - & $16 \times 219$ & - \\
\hline $\begin{array}{l}\text { Short term tensile } \\
\text { strength }^{1}\end{array}$ & $\mathrm{kN} \mathrm{m}^{-1}$ & 58 & 68 & 55 \\
\hline $\begin{array}{l}\text { Short term } \\
\text { tensile strength }{ }^{2}\end{array}$ & $\mathrm{kN} \mathrm{m}^{-1}$ & $54 \cdot 6$ & $52 \cdot 2$ & $69 \cdot 5$ \\
\hline $\begin{array}{l}\text { Strain at maximum } \\
\text { tensile strength }{ }^{1}\end{array}$ & $\%$ & $11 \cdot 5$ & 11 & 105 \\
\hline $\begin{array}{l}\text { Strain at maximum } \\
\text { tensile strength }{ }^{2}\end{array}$ & $\%$ & $10 \cdot 6$ & $12 \cdot 4$ & $100 \cdot 9$ \\
\hline
\end{tabular}
soil $\left(I_{\mathrm{D}}=50 \%\right)$ and the GC under a vertical stress of $5 \mathrm{kPa}$

Table 2 Physical and mechanical properties of the
geosynthetics

${ }^{1}$ Provided by the manufacturer (machine direction).

${ }^{2}$ Obtained in tensile tests performed according to EN ISO 10319 (machine direction)

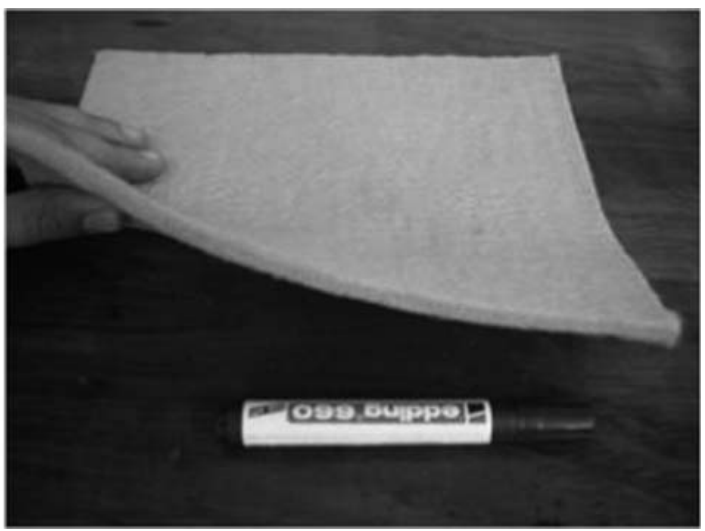




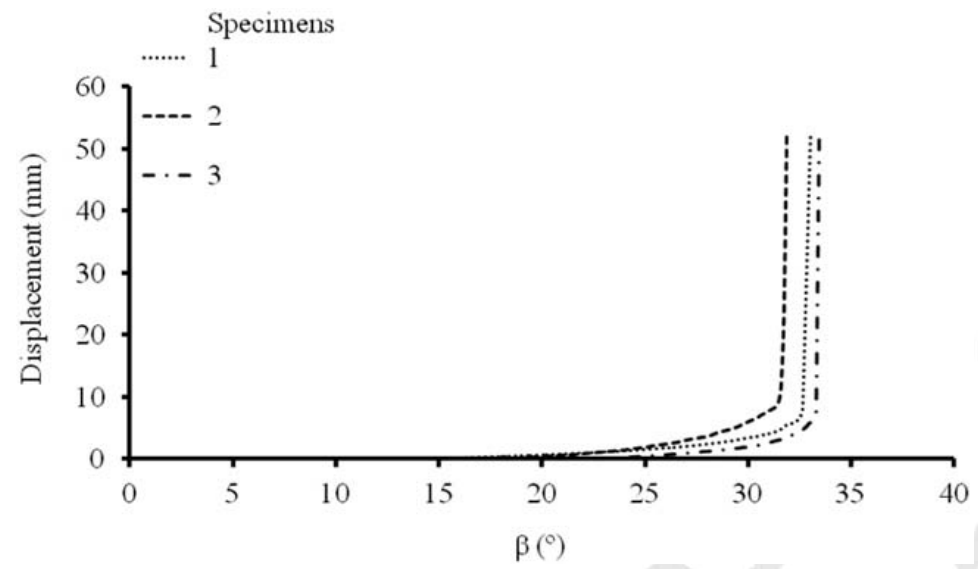

6 Dry soil-GC interface (test T1): variation of the measured upper box displacement with the inclination of the rigid base for the three specimens tested

was $37 \cdot 0^{\circ}$ with a standard deviation of $0 \cdot 9^{\circ}$ and a coefficient of variation of $2 \cdot 4 \%$ (see Table 4 ).

Table 5 shows the mean values of the friction angles at soil-geosynthetic interfaces under different vertical stresses and soil moisture contents for the GC, the non-woven GTX, and the extruded GGR. The coefficients of variation obtained for those values did not exceed $5 \%$.

It can be seen that the friction angle at soil-geosynthetic interfaces decreased with the increase of the vertical stress. The GC and the non-woven GTX exhibited a similar behavior. The increase of soil moisture content induced a slight increase on the friction angle at soil-geosynthetic interfaces for the lowest vertical stress applied $(5 \mathrm{kPa})$ and a slight decrease for the highest vertical stress used $(25 \mathrm{kPa})$.

For the soil-GGR interface, the increase of soil moisture content induced a slight increase on the friction angle for 5 and $10 \mathrm{kPa}$ of vertical stress. This tendency was not observed for the highest vertical stress used $(25 \mathrm{kPa})$.

A different approach to define soil-geosynthetic interface parameters based on the results of inclined plane shear tests was considered.

Table 3 Test program

\begin{tabular}{|c|c|c|c|c|c|c|c|c|}
\hline \multirow[b]{2}{*}{ Test } & \multirow[b]{2}{*}{ Test method } & \multirow[b]{2}{*}{ Geosynthetic } & \multicolumn{2}{|c|}{ Vertical stress $/ \mathrm{kPc}$} & \multirow[b]{2}{*}{25} & \multicolumn{3}{|c|}{ Soil moisture content (\%) } \\
\hline & & & 5 & 10 & & Dry & $1 / 2 w_{\mathrm{opt}}$ & $w_{\mathrm{opt}}$ \\
\hline T1 & 1 & GC & $x$ & & & $x$ & & \\
\hline T2 & 1 & GC & & $x$ & & $x$ & & \\
\hline T3 & 1 & GC & & & $X$ & $x$ & & \\
\hline T4 & 1 & GC & $x$ & & & & $x$ & \\
\hline T5 & 1 & GC & & $X$ & & & $x$ & \\
\hline T6 & 1 & GC & & & $x$ & & $x$ & \\
\hline T7 & 1 & GC & $x$ & & & & & $x$ \\
\hline T8 & 1 & GC & & $x$ & & & & $x$ \\
\hline T9 & 1 & GC & & & $X$ & & & $x$ \\
\hline T10 & 1 & GTX & $x$ & & & $x$ & & \\
\hline T11 & 1 & GTX & & $X$ & & $x$ & & \\
\hline T12 & 1 & GTX & & & $x$ & $x$ & & \\
\hline T13 & 1 & GTX & $x$ & & & & $x$ & \\
\hline T14 & 1 & GTX & & $X$ & & & $x$ & \\
\hline T15 & 1 & GTX & & & $x$ & & $x$ & \\
\hline T16 & 1 & GTX & $x$ & & & & & $x$ \\
\hline T17 & 1 & GTX & & $x$ & & & & $x$ \\
\hline T18 & 1 & GTX & & & $x$ & & & $x$ \\
\hline T19 & 2 & GGR & $x$ & & & $x$ & & \\
\hline T20 & 2 & GGR & & $X$ & & $x$ & & \\
\hline T21 & 2 & GGR & & & $X$ & $x$ & & \\
\hline T22 & 2 & GGR & $x$ & & & & $X$ & \\
\hline T23 & 2 & GGR & & $x$ & & & $x$ & \\
\hline T24 & 2 & GGR & & & $x$ & & $x$ & \\
\hline T25 & 2 & GGR & $x$ & & & & & $x$ \\
\hline T26 & 2 & GGR & & $x$ & & & & $x$ \\
\hline T27 & 2 & GGR & & & $X$ & & & $x$ \\
\hline
\end{tabular}




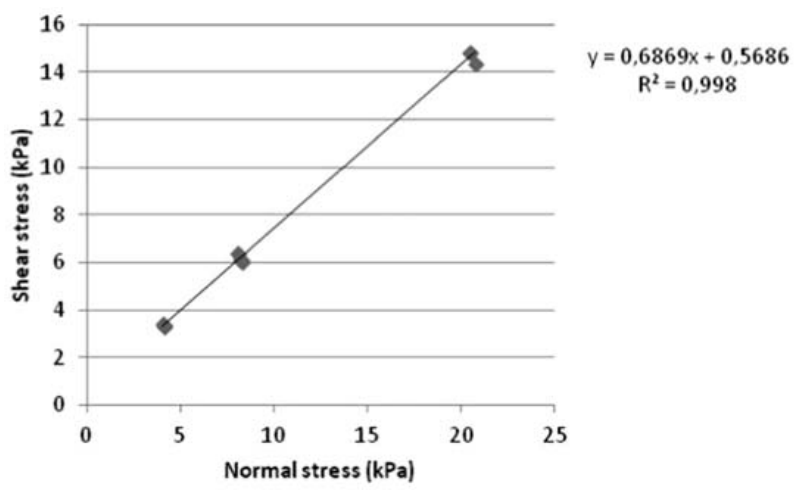

7 Failure envelope for dry soil-geotextile (GTX) interface

Table 4 Results of test T1 (geocomposite (GC), vertical stress of $5 \mathrm{kPa}$, dry soil)

\begin{tabular}{|c|c|c|c|c|c|c|c|c|}
\hline Specimens & $\beta /^{\circ}$ & $\mathrm{Fv} / \mathrm{N}$ & $A / \mathrm{m}^{2}$ & $\sigma_{\mathrm{n}} / \mathrm{kPa}$ & $f(\beta) / \mathrm{N}$ & $\tau / \mathrm{kPa}$ & $\tau / \sigma_{n}$ & $\phi_{\mathrm{sg}} I^{\circ}$ \\
\hline 1 & 33.0 & 450 & 0.09 & $4 \cdot 19$ & 41.63 & $3 \cdot 19$ & $0 \cdot 76$ & 37.3 \\
\hline 2 & 31.9 & 450 & 0.09 & $4 \cdot 25$ & $40 \cdot 37$ & 3.09 & 0.73 & $36 \cdot 0$ \\
\hline 3 & 33.5 & 450 & 0.09 & $4 \cdot 17$ & $42 \cdot 10$ & $3 \cdot 23$ & 0.77 & $37 \cdot 7$ \\
\hline Mean value & $32 \cdot 8$ & & & & & & & $37 \cdot 0$ \\
\hline $\mathrm{SD}^{1}$ & 0.8 & & & & & & & 0.9 \\
\hline $\mathrm{CV}^{2}(\%)$ & $2 \cdot 4$ & & & & & & & $2 \cdot 4$ \\
\hline
\end{tabular}

${ }^{1}$ Standard deviation.

${ }^{2}$ Coefficient of variation.

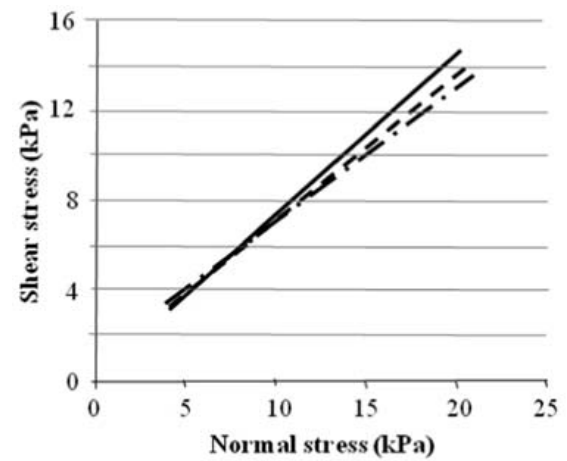

Moisture content: Dry 1/2Wopt --Wopt $-\cdots$

8 Failure envelopes for soil-geocomposite (GC) interfaces

Based on the values of normal and friction stresses of the three tests carried out with a geosynthetic and each value of soil moisture content, the failure envelope was defined (Fig. 7).

Tables 6 and 7 present the values of normal and friction stresses obtained on the inclined plane shear tests of, respectively, the non-woven GTX and the extruded GGR confined by soil with different moisture contents (dry, 1/2 $w_{\text {opt }}$, and $w_{\text {opt }}$ ).

Figure 8 shows the failure envelopes for soil-GC interfaces and Table 8 sums the soil-geosynthetic interfaces friction angle for all the conditions considered in the present research.

Table 5 Mean friction angles of the soil-geosynthetic interfaces

\begin{tabular}{|c|c|c|c|c|c|c|c|c|c|}
\hline \multirow{4}{*}{$\begin{array}{l}\text { Vertical } \\
\text { stress } \\
(\mathrm{kPa})\end{array}$} & \multicolumn{9}{|c|}{ Mean friction angle $/^{\circ}$} \\
\hline & \multicolumn{3}{|l|}{$\mathrm{GC}$} & \multicolumn{3}{|l|}{ GTX } & \multicolumn{3}{|l|}{ GGR } \\
\hline & \multicolumn{9}{|c|}{ Soil moisture content (\%) } \\
\hline & Dry & $1 / 2 w_{\mathrm{opt}}$ & $w_{\text {opt }}$ & Dry & $1 / 2 w_{\mathrm{opt}}$ & $w_{\mathrm{opt}}$ & Dry & $1 / 2 w_{\mathrm{opt}}$ & $w_{\mathrm{opt}}$ \\
\hline 5 & $37 \cdot 0$ & $41 \cdot 4$ & $41 \cdot 0$ & 39.5 & $41 \cdot 7$ & $41 \cdot 0$ & $36 \cdot 5$ & $37 \cdot 8$ & $38 \cdot 8$ \\
\hline 10 & $37 \cdot 2$ & $37 \cdot 1$ & $37 \cdot 1$ & $37 \cdot 1$ & $37 \cdot 7$ & $36 \cdot 9$ & $34 \cdot 4$ & $36 \cdot 3$ & $35 \cdot 9$ \\
\hline 25 & $35 \cdot 6$ & $34 \cdot 4$ & 33.0 & $35 \cdot 6$ & $34 \cdot 6$ & $33 \cdot 1$ & 32.9 & 33.4 & $32 \cdot 6$ \\
\hline
\end{tabular}

Table 6 Values of normal stresses and shear resistances of the soil-geotextile (GTX) interface

\begin{tabular}{|c|c|c|c|c|c|c|c|}
\hline \multirow{3}{*}{$\begin{array}{l}\text { Vertical stress } \\
(\mathrm{kPa})\end{array}$} & \multirow[b]{3}{*}{ Specimen } & \multicolumn{6}{|c|}{ Soil moisture content (\%) } \\
\hline & & \multicolumn{2}{|l|}{ Dry } & \multicolumn{2}{|c|}{$1 / 2 w_{\mathrm{opt}}$} & \multicolumn{2}{|l|}{$w_{\mathrm{opt}}$} \\
\hline & & $\sigma_{\mathrm{n}} / \mathrm{kPa}$ & $\tau / \mathrm{kPa}$ & $\sigma_{n} / \mathrm{kPa}$ & $\tau / \mathrm{kPa}$ & $\sigma_{\mathrm{n}} / \mathrm{kPa}$ & $\tau / \mathrm{kPa}$ \\
\hline 5 & 1 & $4 \cdot 12$ & $3 \cdot 31$ & $4 \cdot 04$ & 3.44 & 4.00 & 3.50 \\
\hline 5 & 2 & $4 \cdot 10$ & 3.35 & 3.95 & 3.58 & 4.08 & $3 \cdot 38$ \\
\hline 5 & 3 & 4.04 & $3 \cdot 44$ & 3.94 & $3 \cdot 60$ & 3.95 & 3.58 \\
\hline 10 & 1 & $8 \cdot 24$ & $6 \cdot 15$ & $8 \cdot 10$ & $6 \cdot 36$ & 8.08 & $6 \cdot 39$ \\
\hline 10 & 2 & $8 \cdot 08$ & $6 \cdot 39$ & $8 \cdot 14$ & $6 \cdot 29$ & $8 \cdot 34$ & $5 \cdot 99$ \\
\hline 10 & 3 & $8 \cdot 28$ & $6 \cdot 08$ & $8 \cdot 18$ & $6 \cdot 23$ & $8 \cdot 25$ & $6 \cdot 13$ \\
\hline 25 & 1 & $20 \cdot 46$ & $14 \cdot 85$ & $20 \cdot 80$ & $14 \cdot 34$ & $21 \cdot 13$ & $13 \cdot 81$ \\
\hline 25 & 2 & $20 \cdot 46$ & 14.85 & $20 \cdot 95$ & $14 \cdot 11$ & $21 \cdot 17$ & $13 \cdot 75$ \\
\hline 25 & 3 & $20 \cdot 77$ & $14 \cdot 39$ & $20 \cdot 62$ & $14 \cdot 61$ & $21 \cdot 17$ & $13 \cdot 75$ \\
\hline
\end{tabular}




\begin{tabular}{|c|c|c|c|c|c|c|c|}
\hline \multicolumn{8}{|c|}{ Soil moisture co } \\
\hline & & Dry & & $1 / 2 w_{\mathrm{opt}}$ & & $w_{\text {opt }}$ & \\
\hline (kPa) & Specimen & $\sigma_{\mathrm{n}} / \mathrm{kPa}$ & $\tau / \mathrm{kPa}$ & $\sigma_{\mathrm{n}} / \mathrm{kPa}$ & $\tau / \mathrm{kPa}$ & $\sigma_{n} / \mathrm{kPa}$ & $\tau / \mathrm{kPa}$ \\
\hline 5 & 1 & $4 \cdot 30$ & $2 \cdot 98$ & $4 \cdot 26$ & 3.06 & $4 \cdot 12$ & $3 \cdot 31$ \\
\hline 5 & 2 & $4 \cdot 18$ & $3 \cdot 21$ & $4 \cdot 12$ & $3 \cdot 31$ & $4 \cdot 13$ & 3.29 \\
\hline 5 & 3 & $4 \cdot 20$ & $3 \cdot 18$ & $4 \cdot 11$ & $3 \cdot 33$ & $4 \cdot 10$ & $3 \cdot 34$ \\
\hline 10 & 1 & $8 \cdot 42$ & $5 \cdot 85$ & $8 \cdot 21$ & $6 \cdot 19$ & $8 \cdot 14$ & $6 \cdot 31$ \\
\hline 10 & 2 & $8 \cdot 45$ & $5 \cdot 79$ & $8 \cdot 44$ & $5 \cdot 82$ & $8 \cdot 33$ & 6.00 \\
\hline 10 & 3 & $8 \cdot 48$ & $5 \cdot 74$ & $8 \cdot 18$ & $6 \cdot 24$ & 8.48 & $5 \cdot 76$ \\
\hline 25 & 1 & $21 \cdot 22$ & $13 \cdot 67$ & 20.97 & 14.07 & $21 \cdot 23$ & $13 \cdot 65$ \\
\hline 25 & 2 & $21 \cdot 14$ & $13 \cdot 80$ & $20 \cdot 92$ & $14 \cdot 16$ & $21 \cdot 22$ & $13 \cdot 67$ \\
\hline 25 & 3 & $21 \cdot 24$ & $13 \cdot 64$ & $21 \cdot 32$ & $13 \cdot 50$ & $21 \cdot 31$ & 13.51 \\
\hline
\end{tabular}

The friction angle at soil-geosynthetic interfaces $\left(\phi_{\mathrm{sg}}\right)$ decreased with the increase of the moisture content of the soil for the GC and for the non-woven GTX. The influence of geosynthetic type on the interface resistance was negligible for those two materials.

The influence of the soil moisture content was less evident on the soil-GGR interface. In fact, similar values of the friction angle $\left(\phi_{\mathrm{sg}}\right)$ were observed for dry and $1 / 2$ $w_{\text {opt }}$ soil moisture contents. For the highest soil moisture content $\left(w_{\text {opt }}\right)$ a slight decrease of the friction angle was registered.

For the soil-GGR inclined plane shear resistance, the soil-soil friction at the GGR apertures is of utmost importance as the solid lateral surface of the geosynthetic is smaller than the apertures lateral surface. On the other hand, the solid lateral surface of the GGR is smoother than the lateral surface of the GC or GTX. Both conditions, associated with the high percentage of fines of the soil used $\left(D_{50}=1.00 \mathrm{~mm}\right)$, justified the lower dry soil-GGR interface resistance when compared with the other dry soil-geosynthetic interfaces.

\section{Conclusion}

This paper deals with inclined plane shear on three different geosynthetics (a GC, a non-woven GTX, and an extruded GGR) with a residual soil from granite. The influence of soil moisture content and geosynthetic type on soil-geosynthetic interaction behavior in inclined plane shear was discussed by analyzing the results of the inclined plane shear tests.
Based on the presented results the main conclusions can be put forward.

- the influence of soil moisture content was relevant for the soil-GTX and soil-GC interfaces;

- in fact, in both cases the interface resistance decreased more than $10 \%$ when soil moisture content changed from dry to optimum $\left(w_{\text {opt }}\right)$;

- no significant differences were observed between the interfaces with the GC and with the GTX;

- the influence of soil moisture content on the behavior of the soil-GGR interface was less evident; only for the highest soil moisture content $\left(w_{\text {opt }}\right)$ a slight decrease (about $3 \%$ ) on the interface friction angle was observed;

- the dry soil-GGR interface resistance was lower than that observed for the GC and for the GTX due to the relevance of soil-soil friction at the GGR apertures, to the high percentage of fines of the soil used in the research $\left(D_{50}=1.00 \mathrm{~mm}\right)$ and to the smoother solid lateral surface of the GGR when compared with that of the other two geosynthetics.

\section{Acknowledgements}

The authors acknowledge the support of the research projects COMPETE: FCOMP-01-0124-FEDER-009750 (Ref. FCT PTDC/ECM/100975/2008) and COMPETE: FCOMP-010124-FEDER-028842 (Ref. FCT PTDC/ECM-GEO/0622/ 2012). Fernanda Ferreira and José Ricardo Carneiro would like to thank 'FCT - Fundação para a Ciência e a Tecnologia' for their research grants (SFRH/BD/72886/2010 and SFRH/ BPD/88730/2012, respectively).

Table 8 Friction angles of soil-geosynthetic interfaces obtained from failure envelops

\begin{tabular}{|c|c|c|c|c|c|c|c|c|c|}
\hline \multirow{3}{*}{$\begin{array}{l}\text { interface } \\
\text { parameter }\end{array}$} & \multicolumn{3}{|l|}{ GC } & \multicolumn{3}{|l|}{ GTX } & \multicolumn{3}{|l|}{ GGR } \\
\hline & \multicolumn{9}{|c|}{ Soil moisture content (\%) } \\
\hline & Dry & $1 / 2 w_{\mathrm{opt}}$ & $w_{\mathrm{opt}}$ & Dry & $1 / 2 w_{\mathrm{opt}}$ & $w_{\mathrm{opt}}$ & Dry & $1 / 2 w_{\mathrm{opt}}$ & $w_{\mathrm{opt}}$ \\
\hline$\phi_{\text {sg }}\left({ }^{\circ}\right)$ & $35 \cdot 0$ & $32 \cdot 6$ & $30 \cdot 7$ & 34.5 & $32 \cdot 7$ & $30 \cdot 8$ & $31 \cdot 9$ & $32 \cdot 0$ & $30 \cdot 8$ \\
\hline
\end{tabular}




\section{References}

Briançon, L., Girard, H. and Gourc, J. P. 2011. A new procedure for measuring geosynthetic friction with an inclined plane, Geotext. Geomembr., 29, (5), 472-482.

Briançon, L., Girard, H. and Poulin, D. 2002. Slope stability of lining systems - experimental modelling of friction at geosynthetic interfaces, Geotext. Geomembr., 20, (3), 147-172.

Costa-Lopes, P. C., Lopes, M. L. and Lopes, M. P. 2001. The inclined plane shear behaviour of geosynthetics - influence of soil particles size and geosynthetic structure. Geosynth. Int., 8, (4), 327-342.

Eid, H. T. 2011. Shear strength of geosynthetic composite systems for design of landfill liner and cover slopes, Geotext. Geomembr., 29, (3), 335-344.

Izgin, M. and Wasti, Y. 1998. Geomembrane - sand interface frictional properties as determined by inclined board and shear box tests, Geotext. Geomembr., 16, (4), 207-219.

Lopes, M. L. 2013. Friction at geosynthetic interfaces on inclined plane shear, Indian Geotech. J., 43, (4), 321-330.

Narejo, D. B. 2003. A simple tilt table device to measure index friction angle of geosynthetics, Geotext. Geomembr., 21, (1), 49-57.
Palmeira, E. M., Lima, N. R. Jr. and Mello, L. G. R. 2002. Interaction between soils and geosynthetic layers in large-scale ramp tests, Geosynth. Int., 9, (2), 149-187.

Pitanga, H. N., Gourc, J. P. and Vilar, O. M. 2009. Interface shear strength of geosynthetics: evaluation and analysis of inclined plane tests, Geotext. Geomembr., 27, 6, 435-446.

Reyes Ramirez, R. and Gourc, J. P. 2003. Use of inclined plane test in measuring geosynthetic interface friction relationships, Geosynth. Int., 10, (5), 165-175.

Wasti, Y. and Özdüzgün, Z. B. 2001. Geomembrane-geotextile interface shear properties as determined by inclined board sand hear box tests, Geotext. Geomembr., 19, (1), 45-57. STANDARDS

EN ISO 12957-2. 2004. Geotextiles and geotextile-related products determination of friction characteristics - part 2: inclined plane test. European Committee for Standardization in collaboration with the International Standardization Organization, Brussels.

EN ISO 10319. 2008. Geosynthetics - wide-width tensile tests. European Committee for Standardization in collaboration with the International Standardization Organization, Brussels. 